\title{
Cost Aware Expansion Planning with Renewable DGs using Particle Swarm Optimization and Cuckoo Search Algorithm
}

\author{
Hanumesh*, Dr.Sudarshana Reddy H.R** \\ * Departement of Electrical and Electronics Engineering, Government Polytechnic, Kustagi, Karnataka,India \\ ** Departement of Electrical and Electronics Engineering, University B. D .T College of Engineering, \\ Davanagere, India
}

\begin{abstract}
This Paper is an attempt to develop the expansion-planning algorithm using meta heuristics algorithms. Expansion Planning is always needed as the power demand is increasing every now and then. Thus for a better expansion planning the meta heuristic methods are needed. The cost efficient Expansion planning is desired in the proposed work. Recently distributed generation is widely researched to implement in future energy needs as it is pollution free and capability of installing it in rural places. In this paper, optimal distributed generation expansion planning with Particle Swarm Optimization (PSO) and Cuckoo Search Algorithm (CSA) for identifying the location, size and type of distributed generator for future demand is predicted with lowest cost as the constraints. Here the objective function is to minimize the total cost including installation and operating cost of the renewable DGs. MATLAB based 'simulation using M-file program is used for the implementation and Indian distribution system is used for testing the results.
\end{abstract}

Keyword: PSO, CSA Expansion Planning Renewable DGs Indian distribution system

\section{INTRODUCTION}

A constrained multi-objective expansion planning of the power system with the renewable energy resources is discussed in the literature [1]. Particle Swarm Optimisation (PSO) based planning is carried out and the tradeoff between the economic ratio, voltage stability factor and the security index were considered. The literature [2] discusses the multi objectives like the reliability of service, system operational efficiency, the cost of the purchased energy, power quality constraint and the system security constraints and the optimized expansion planning is carried out. Both [1] and [2] senses the highest impacting bus and places the DG in that bus .The literature [3] is incorporated with the evolutionary algorithm for the implementation of the placement of renewable Distributed Generator in the radial distribution system by considering the constraints like the sensitivity analysis. The sensitivity analysis gives idea about multiple places where the DGs can be placed [3], while curtailment and clipping of the wind turbine is adopted in order to avoid the wind turbine output to be used for a certain fraction of the output. Generator dispatch problems are solved with multi objective in [5]. Placement of wind and solar alone with its mathematical static model is implemented by kayal [6]. This improves the voltage stability and power loss minimization. The Evolutionary algorithms play an important role in placement problems, as it is easy to consider more constraints and fast solution. [3,4]. The charateristics of the uncertain nature of the renewable energy based power plant is used to create the constraints of the optimization using Stochastic programming (SP) [7]-[9] and robust optimization (RO) [10]-[15] is included in the expansion planning problem.

In this paper cuckoo search algorithm [16] is used for the first time in optimal expansion planning of DGs with renewable energy resources. And the problem of the minimization is solved by Partha kayal [1] is modified with solving method by using CSA and PSO to get better voltage profile and voltage stability factor and reduced loss.

\section{PROBLEM FORMULATION}

The optimization algorithm contains two portions of the formulation one is the objective function and the other one is the constraints. The objective functions and the constraints of this paper is referred form the literature [1]. The objective function is formulated with total cost of renewable DGs due to installation, operation, maintenance, cost benefit and voltage stability. The equations are given below [1].

2.1 Total cost of renewable DGs due to installation, operation and maintenance,

The equation (1) defines the total cost due to the installation, operation and maintainance of the renewable energy based power plant used for the expansion planning. Thus the objective function is the cost function which dependent on the variables 
like the installation cost, operation cost and the maintenance cost.

$$
\begin{aligned}
& \text { Cost }_{D G \text { ren }}=\sum_{i=2}^{N} \sum_{j \in t_{y p e}} I C_{i j} * n_{i} * l_{i}+ \\
& \left(\sum_{i=2}^{N} \sum_{j \in t y p e} O M C_{i j} * P_{D G \text { ren } i j} * n_{i} * l_{i}\right) * C P V
\end{aligned}
$$

Where,

$I C_{i j}$ Inverstment cost type ${ }^{J_{j}^{*}}$ renewable $D G$ at bus

OMC. -

Opsration and maintenance cost of typg Ijrenswable DG at bus'

$n_{i}-$ number of DG unit connected at bus ${ }^{\prime \prime} i^{t}$

$l_{i}$ - location variable at bus ${ }^{i t}(0$ or 1$)$

$P_{D G \text { renij }}-$

Power generated by type ${ }^{\prime \prime} j^{t} D G$ at bus ${ }^{\prime \prime} i^{t}$

$N-$ number of buses in the network

CPV - cumulative present value

$$
C P V=\frac{\left(1-P V^{\left.\mathbb{N}_{y}\right)}\right.}{(1-P V)}
$$

Here,

Present value of cost

$$
P V=\frac{1+\frac{\pi F}{100}}{1+\frac{F R}{100}}
$$

Where,

$$
\begin{aligned}
& \text { IF - Inflation rate } \\
& \text { IR - interest rate } \\
& N_{y}-\text { Number of year in planning horizon }
\end{aligned}
$$

\subsection{Total benefit that can be achieved from operation of distribution network with renewable DGs}

The equations are given below [1]. The total benefit that can be obtained for the operation of the distribution network with the renewable energy based DGs is given as the constraint that affects the operation of the optimization as below. The equation (4) measures the total benefit that is obtained by using the renewable energy considering both the useful power and the power loss. The total power that is generated multiplied with the cost of electricity is used to find the total benefit of the renewable energy based power plant that is placed in the optimized location.

It is given by,

$$
\begin{aligned}
& \text { Benefit } \\
& \left.\left.l_{i}\right)+\Delta \text { Ploss ren }_{D G \text { ren }}\right\} *\left\{\left(\sum_{\mathrm{i}=2}^{\mathrm{N}} \sum_{\mathrm{j} \in \mathrm{type}} P_{D G \text { ren ij }} * 8760 * C P V\right.\right.
\end{aligned}
$$

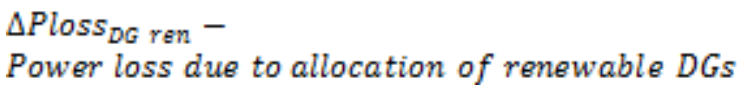

(5)

Distribution Companies gets benefited more when $B C R_{D G \text { ren }}>1$

\subsection{Voltage stability factor(VSF)}

As the reactive power in the buses are dependent on the change in the voltage in different buses, steps must be taken to have a constant or nearly constant voltage in the power system. Thus voltage stability plays a major role in the implementation of the expansion planning of the renewable energy based implementation. Due to the placement of DGs in power system changes the voltage profile so there is a need for improving the voltage profile, the below equation shows the VSF for any bus $\mathrm{i}+1$ in the distribution network,

$$
V S F_{i+1}=\left(2 V_{i+1}-V_{i}\right)
$$

Here

$$
\begin{aligned}
& V_{i}-\text { voltage magnitude at bus } i \\
& V_{i+1}-\text { voltage magnitude at bus } i+1 \\
& \text { VSF for the entire network is given by } \\
& V S F=\frac{\sum_{i=1}^{N-1} V S F_{i+1}}{(N-1)}
\end{aligned}
$$

\subsection{Network security index}

Network Security Index (NSI) comprises the consideration of the average line loading for all the lines considered cumulatively. The Line Loading $\left(\mathrm{LL}_{\mathrm{i}}\right)$ is defined as in (8),

$$
L L_{\mathrm{i}}=\frac{L_{M V A, i}}{L_{M V A_{\max i}}}
$$

Network security index can be formulated as the average of the line loading by cumulating the line loading of all the buses while placing the DGs.

$$
N S I=\frac{\sum_{i=1}^{\mathbb{N}-1} U L_{i}}{(\mathbb{N}-1)}
$$

The constraint for the optimization is fixed in such a way that, lower the NSI better is the placement possibility.

\section{So,}

the objective function is represented as minimize $f\left(P_{D G} \operatorname{renij}, n_{\mathrm{i}}, l_{i}\right)=-B C R-V S F+$
NSI

with respect to equality constraints, 
$P_{\text {slack }}+\left(\sum_{\mathrm{i}=2}^{\mathrm{N}} \Sigma_{j \in \mathrm{j} y p g} P_{D G \text { renij }} * n_{\mathrm{i}} * l_{\mathrm{i}}\right)-$ $\sum_{\mathrm{i}=2}^{\mathrm{W}} P_{D, \mathrm{i}}-P_{L}=0$

$$
Q_{\text {slack }}-\sum_{i=2}^{N} Q_{D i}-P_{L}=0
$$

Inequality constraints, Generation limit at bus $\mathrm{i}$

$P_{D G \text { renif }} * n_{\mathrm{i} \text { min }} \leq P_{D G \text { reni } i j} * n_{\mathrm{i}} \leq P_{D G \text { renij }}$ $n_{\mathrm{i} \max }$

Bus voltage tolerance constraint at bus $\mathrm{i}$ $V_{i, \min } \leq V_{i} \leq V_{i, \max }$

(14)
Line capacity constraint of line connecting bus $\mathrm{i}$ and bus $\mathrm{j}$

$$
S_{i j} \leq S_{i j}^{\max }
$$

Where $S_{i j}$ and $S_{i j}{ }^{\max }$ are actual and maximum line power flow in MVA

\section{SOLUTION METHODS}

Here to solve the problem formulated PSO and CSA *techniques are used. Those techniques are explained detaily in 3.1 and 3.2 subsections.

3.1. Particle Swarm Optimization [8]

The PSO technique the position of each particle corresponds to the solution variables which get updated in each particle movement. flow chart of $\mathrm{PSO}$ algorithm is given in figure 1

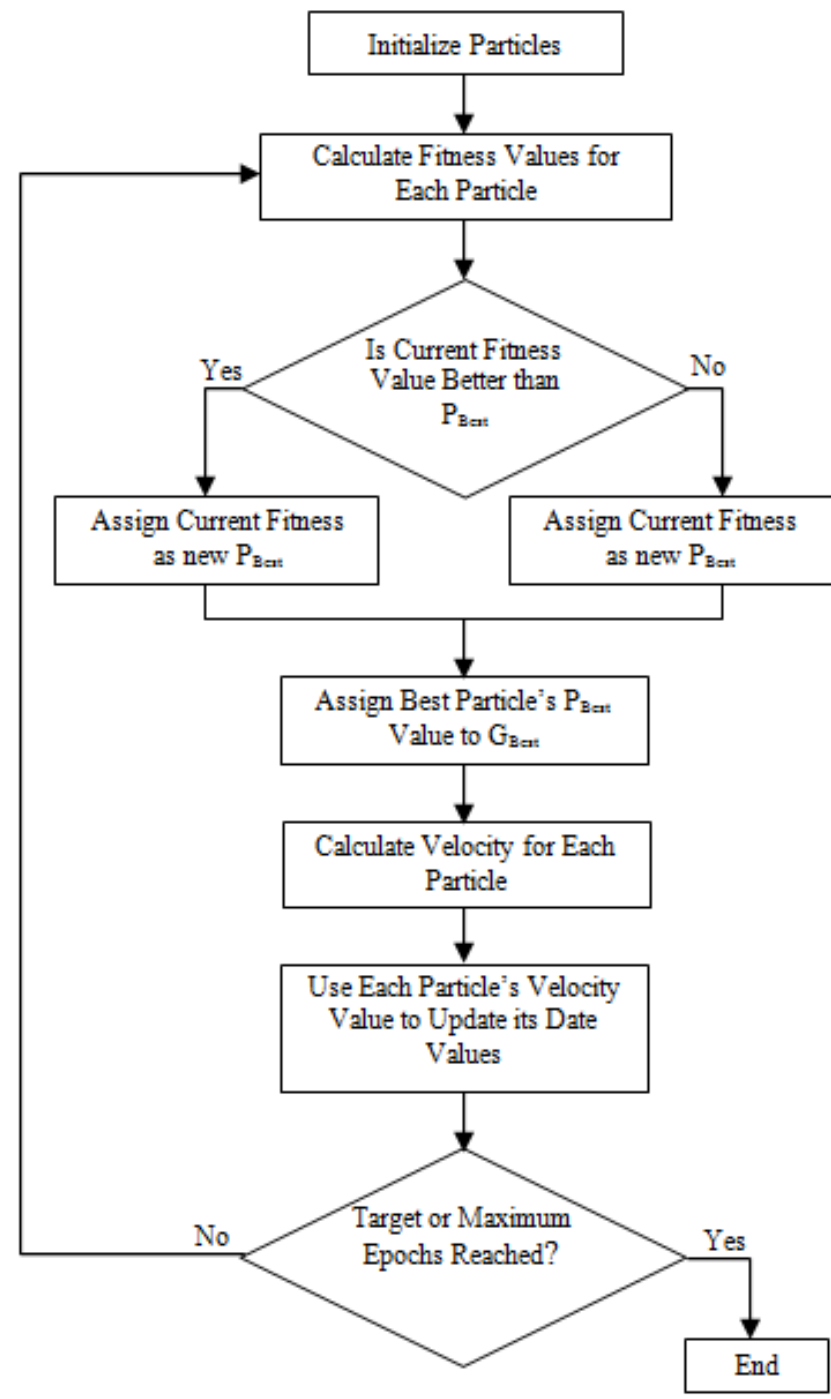

Figure 1. Flowchart of particle swarm optimization

\subsection{Cuckoo Search Algorithm [7]}

CSA is a population-based algorithm, in a way similar to GA and PSO, but it uses some sort of elitism and/or selection similar to that used in harmony search. The randomization is more efficient as the step length is heavy-tailed, and any large step is possible. The number of parameters to be tuned is less than GA and PSO, and thus it is 
potentially more generic to adapt to a wider class of optimization problems. In addition, each nest can - Algorithm

Step-1: Assume the $\mathrm{n}$ host nests $\mathrm{Xi}(\mathrm{i}=1,2, . \mathrm{n})$ and maximum number of iteration.

Step-2: Check for maximum number of iterations and select a cuckoo randomly by levy flights evaluate the fitness or cost function (Fi).

Step-3: Choose a nest among $n$ randomly say $(j)$.

Step-4: Check if Fi is less than Fj replace $\mathrm{j}$ by new solution.

Step-5: A fraction of $(\mathrm{Pa})$ worst nest is abandoned and new ones are built. Keep the best nest or solutions

Step-6: Rank the solutions and find the current best. represent a set of solutions, CS can thus be extended to the type of meta-population algorithm. Step-7: Do it for all the iterations and end when the maximum iterations are reached.

Step-8: Display the results.

\section{RESULTS AND DISCUSSION}

The test system used here is Indian 28 distributed bus system [2] (appendix II). The minimization of Equation (10) is implemented with PSO algorithm and CSA algorithm. The number of DG installed is taken constant $(\mathrm{N}=6)$ as 6 . And the problem is solved for 10 years (yr) duration $(\mathrm{Nyr}=10)$. The types of DGs are chosen as Solar, Wind and biomass. Here type ' 1 ' is solar, type ' 2 ' is wind and type ' 3 ' is biomass. Appendix 1 shows the parameters used for it [1]

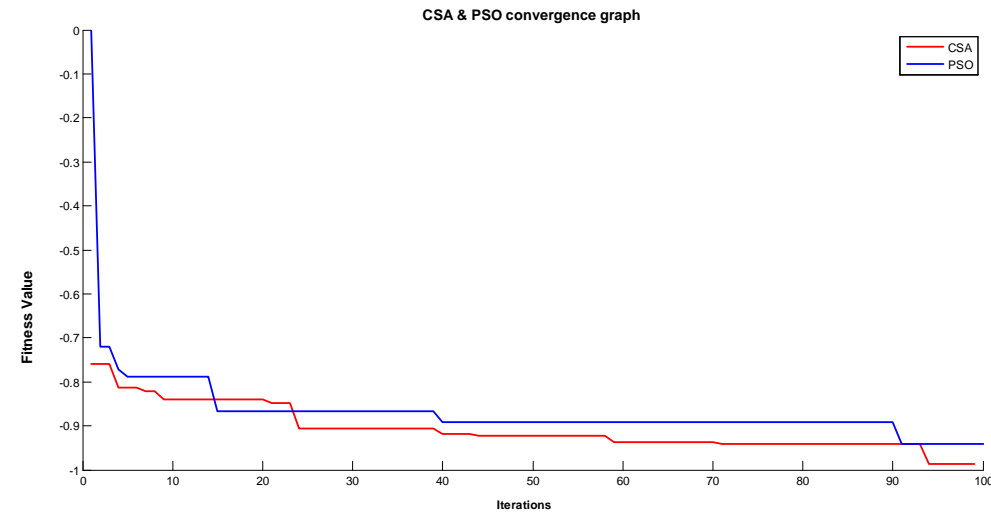

Figure 3. Convergence graph of CSA and PSO

The above fig shows the convergence graph of CSA and PSO algorithm with same objective function. Here total number of population is taken as 60 and iteration count as 100 for both the algorithm. The above graph shows the performance of CSA in red line and PSO in blue line. For 100 iteration CSA gives better minimum objective function. Both satisfies the constraints.

Table 1. Results of PSO algorithm

\begin{tabular}{|l|l|l|l|l|l|l|}
\hline Bus & nos. & type & $\begin{array}{l}\text { Size } \\
(\mathrm{MW})\end{array}$ & IC in Rs & $\begin{array}{l}\text { OMC in } \\
\text { Rs/yr }\end{array}$ & $\begin{array}{l}\text { TC } \\
\text { Rs/yr }\end{array}$ \\
\hline 18 & 2 & 2 & 0.25 & 37500 & 5913 & 43413 \\
\hline 21 & 6 & 2 & 0.75 & 337500 & 53217 & 390717 \\
\hline 15 & 6 & 3 & 1.2 & 720000 & 110376 & 830376 \\
\hline 14 & 6 & 2 & 0.75 & 337500 & 53217 & 390717 \\
\hline 26 & 5 & 3 & 1 & 500000 & 76650 & 576650 \\
\hline 25 & 6 & 2 & 0.75 & 337500 & 53217 & 390717 \\
\hline & & Total & 4.7 & 2270000 & 352590 & 2622590 \\
\hline
\end{tabular}

Table 2. Results of CSA algorithm

\begin{tabular}{|l|l|l|l|l|l|l|}
\hline Bus & nos. & type & $\begin{array}{l}\text { Size } \\
(\mathrm{MW})\end{array}$ & $\begin{array}{l}\text { IC in } \\
\text { Rs/MW }\end{array}$ & $\begin{array}{l}\text { OMC in } \\
\text { Rs/yr }\end{array}$ & $\begin{array}{l}\text { TC } \\
\text { Rs/yr }\end{array}$ \\
\hline 25 & 5 & 3 & 1 & 500000 & 76650 & 576650 \\
\hline 18 & 5 & 3 & 1 & 500000 & 76650 & 576650 \\
\hline 19 & 3 & 3 & 0.6 & 180000 & 27594 & 207594 \\
\hline 26 & 5 & 3 & 1 & 500000 & 76650 & 576650 \\
\hline 21 & 5 & 3 & 1 & 500000 & 76650 & 576650 \\
\hline
\end{tabular}




\begin{tabular}{|l|l|l|l|l|l|l|}
\hline 12 & 6 & 2 & 0.75 & 337500 & 53217 & 390717 \\
\hline & & Total & 5.35 & 2517500 & 387411 & 2904911 \\
\hline
\end{tabular}

Table 3. Comparison with PSO Vs CSA

\begin{tabular}{|c|c|c|c|c|c|c|c|}
\hline & loss in MW & BCR & VSF & NSI & Final obj & Time in sec & TC in Rs. \\
\hline CSA & 0.0148 & 1.072 & 0.9736 & 0.0937 & -0.9872 & 684.844965 & 2904911 \\
\hline PSO & 0.0202 & 1.016 & 0.9672 & 0.1282 & -0.9406 & 239.384101 & 2622590 \\
\hline
\end{tabular}

Table I shows the results of PSO algorithm with position, numbers, type, IC, OMC and TC. Table II shows the results of CSA algorithm with position, numbers, type, IC, OMC and TC. Table III shows the comparative results of CSA Vs PSO with TC (Total Cost), Time taken, final objective value, NSI, VSF, BCF and Loss in MW

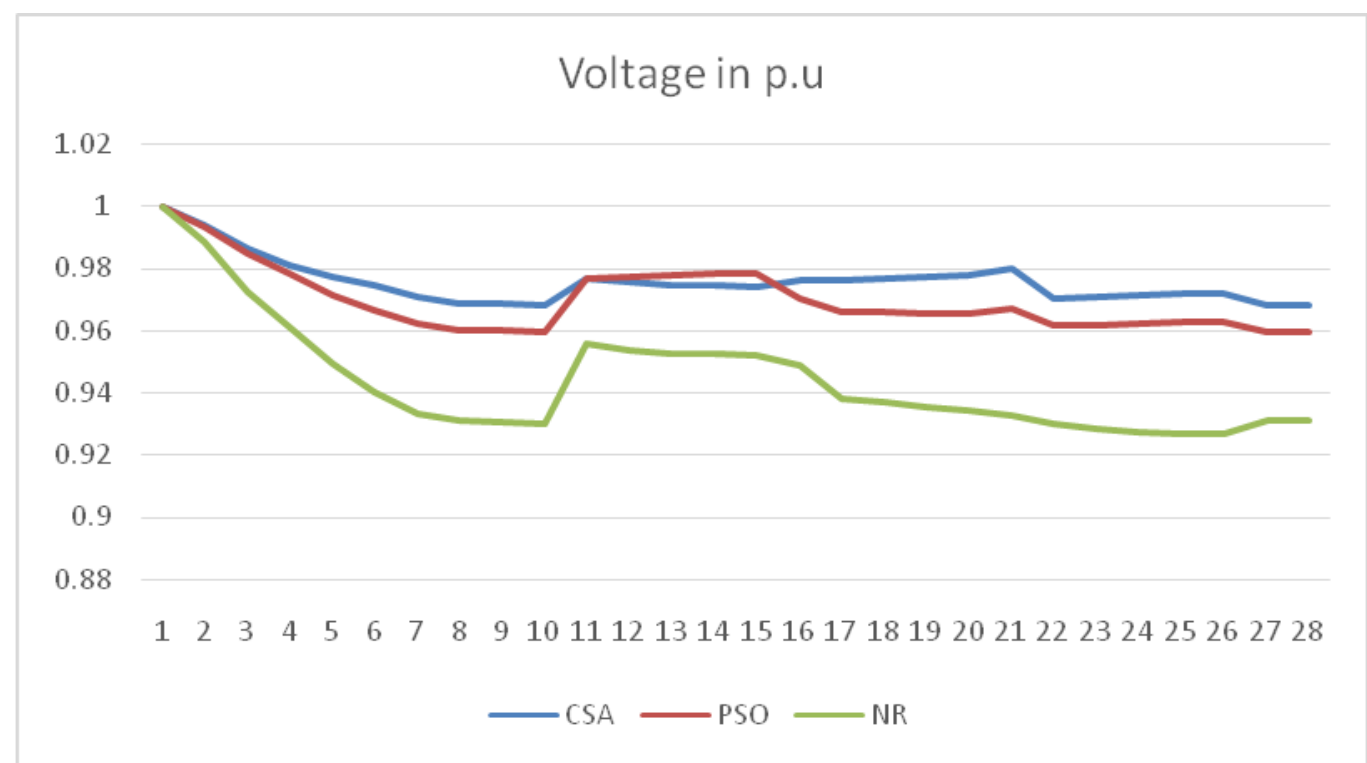

Figure 4. Voltage Profile of Indian 28 bus system for with renewable DG placed optimally with CSA, PSO and without renewable DG with NR (Newton-Raphson) method

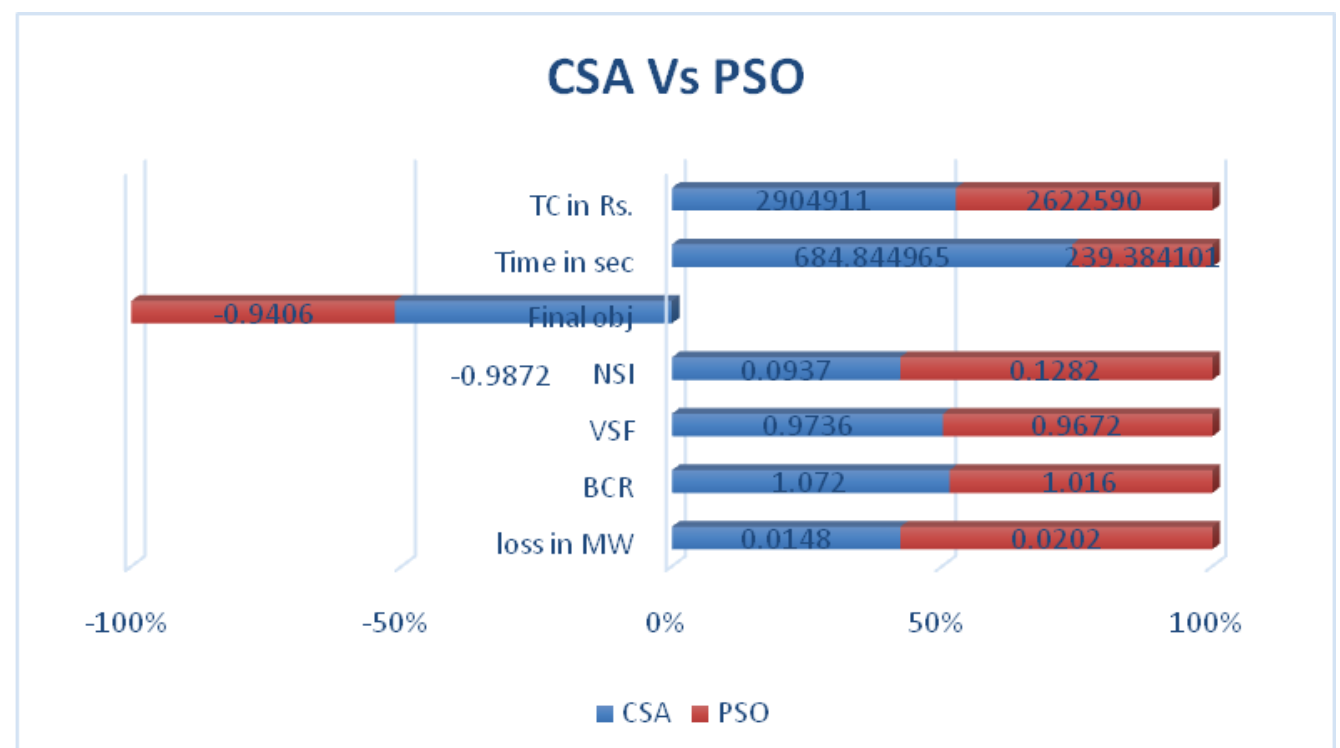

Figure 5. Comparison of CSA Vs PSO with TC (Total Cost), Time taken, final objective value, NSI, VSF, BCF and Loss in MW 
CSA algorithm gives better voltage profile, NSI, VSF and BCR value compared to PSO algorithm. But PSO algorithm gives lesser cost and lesser time taken for solving the algorithm. So, the total cost of

\section{CONCLUSION}

For Indian 28 bus system expansion planning is conducted for 10 year duration to identify the total cost, Network security index and loss reduction and to improve the voltage stability factor, benefit cost ratio. Traditional PSO algorithm and cuckoo search algorithm is used to solve this problem. And comparatively CSA gives better VSF, NSI and voltage profile compared to PSO. And PSO gives lesser cost and lesser time to solve the problem. So for implementation choice of algorithm can be chosen based on the real time requirement.

\section{REFERENCES}

[1]. Partha Kayal, Tanushree Bhattacharjee \& Chandan Kumar Chanda, "Planning of renewable DGs for distribution network considering load model: a multi-objective approach", Energy Procedia 54 (2014) 85 96

[2]. RAJ KUMAR SINGH and S. K. GOSWAMI, "Multi-objective Optimization of Distributed Generation Planning Using Impact Indices and Trade-off Technique" Electric Power Components and Systems, 39:1175-1190, 2011

[3]. Kathod DK, Pant V, Sharma J. Evolutionary programming based optimal placement of renewable distributed generators. IEEE Trans. on Power Syst 2013; 28:683-695.

[4]. Arya LD, Koshti A, Choube SC. "Distributed generation planning using differential evolution accounting voltage stability consideration". Int. J. of Electr. Power Energy Syst 2012; 42:196-207.

[5]. Guo CX, Bai YH, Zheng X, Zhan JP, Wu $\mathrm{QH}$. "Optimal generation dispatch with renewable energy embedded using multiple objectives". Int. J. of Electr. Power Energy Syst 2012; 42:440-447.

[6]. Kayal P, Chanda CK. "Placement of wind and solar based DGs in distribution system for power loss minimization and voltage stability improvement". Int. J. of Electr. Power Energy Syst 2013; 53:795-809.

[7]. L. Baringo and A. J. Conejo, "Transmission and wind power investment," IEEE Trans. Power Syst., vol. 27, no. 2, pp. 885-893, the renewable Dgs per year is less in PSO and more in CSA.

May 2012.

[8]. H. Park, R. Baldick, and D. P. Morton, "A stochastic transmission planning model with dependent load and wind forecasts," IEEE Trans. Power Syst., vol. 30, no. 6, pp. 30033011, Nov. 2015.

[9]. I. Konstantelos and G. Strbac, "Valuation of flexible transmission investment options under uncertainty," IEEE Trans. Power Syst., vol. 30, no. 2, pp. 1047-1055, March 2015.

[10]. R. A. Jabr, "Robust transmission network expansion planning with uncertain renewable generation," IEEE Trans. Power Syst., vol. 28, no. 4, pp. 4558-4567, Nov. 2013.

[11]. B. Chen, J. Wang, L. Wang, Y. He, and Z. Wang, "Robust optimization for transmission expansion planning: minimax cost vs. minimax regret," IEEE Trans. Power Syst., vol. 29, no. 6, pp. 3069-3077, Nov. 2014.

[12]. C. Ruiz and A. J. Conejo, "Robust transmission expansion planning," Euro. $J$. Opr. Res., vol. 242, no. 2, pp. 390-401, April 2015.

[13]. A. Moreira, A. Street, and J. M. Arroyo, “An adjustable robust optimization approach for contingency-constrained transmission expansion planning," IEEE Trans. Power Syst., vol. 30, no. 4, pp. 2013-2022, July 2015.

[14]. R. Mínguez and R. García-Bertrand, "Robust transmission network expansion planning in energy systems: Improving computational performance," Euro. J. Opr. Res., vol. 248, no. 1, pp. 21-32, Jan. 2016.

[15]. B. Chen and L. Wang, "Robust transmission planning under uncertain generation investment and retirement," IEEE Trans. Power Syst., vol. 31, no. 6, pp. 5144-5152, Nov. 2016

[16]. Xin-She Yang, "Cuckoo Search via Levy Flights", 2009, World Congress on Nature \& Boilogically Inspired Computing $(\mathrm{NaBIC})$

[17]. Singaresu S. Rao, “ Engineering Optimization: Theory and practice", Fouth edition, John Wiley \& Sons, Inc. 2009

\section{Appendix I}

Table 3. Technical and economic data of wind and solar based renewable DGs 


\begin{tabular}{|c|c|c|c|c|}
\hline DG technology & $\begin{array}{c}\text { Commercial } \\
\text { size }(\mathbf{k W})\end{array}$ & $\begin{array}{c}\text { Plant } \\
\text { factor (\%) }\end{array}$ & $\begin{array}{c}\text { Investment } \\
\text { cost (Rs/kW) }\end{array}$ & $\begin{array}{c}\text { Operating } \\
\text { and maintenance } \\
\text { cost (Rs/kW-year) }\end{array}$ \\
\hline Solar photovoltaic (PV) & 20 & 25 & 350000 & 4818 \\
\hline Wind turbine & 125 & 20 & 75000 & 11826 \\
\hline Biomass & 200 & 60 & 100000 & 15330 \\
\hline
\end{tabular}

\section{Appendix II}

Table 4. Indian 28-bus distribution system with

Base MVA $=1 \mathrm{MW} \&$ Base Voltage $=11 \mathrm{KV}$

\begin{tabular}{|c|c|c|c|c|c|}
\hline Bus no. & $\begin{array}{c}\text { Power } \\
\text { demand in } \mathrm{MW}\end{array}$ & $\begin{array}{c}\text { From } \\
\text { bus }\end{array}$ & To bus & $\mathbf{R}$ in p.u & $\mathrm{X}$ in p.u \\
\hline 1 & 0.0504 & 1 & 2 & 0.009744 & 0.006777 \\
\hline 2 & 0.02 & 2 & 3 & 0.014843 & 0.010174 \\
\hline 3 & 0.0504 & 3 & 4 & 0.010793 & 0.007397 \\
\hline 4 & 0.02 & 4 & 5 & 0.015298 & 0.010463 \\
\hline 5 & 0.0504 & 5 & 6 & 0.012595 & 0.008628 \\
\hline 6 & 0.0504 & 6 & 7 & 0.015744 & 0.010785 \\
\hline 7 & 0.0504 & 7 & 8 & 0.009893 & 0.006777 \\
\hline 8 & 0.02 & 8 & 9 & 0.005397 & 0.003694 \\
\hline 9 & 0.02 & 9 & 10 & 0.009446 & 0.006471 \\
\hline 10 & 0.08 & 4 & 11 & 0.023331 & 0.009686 \\
\hline 11 & 0.054 & 11 & 12 & 0.009785 & 0.004058 \\
\hline 12 & 0.054 & 12 & 13 & 0.008281 & 0.003438 \\
\hline 13 & 0.02 & 13 & 14 & 0.00376 & 0.001562 \\
\hline 14 & 0.0504 & 14 & 15 & 0.004512 & 0.001876 \\
\hline 15 & 0.0504 & 5 & 16 & 0.021074 & 0.008744 \\
\hline 16 & 0.0128 & 6 & 17 & 0.011289 & 0.004686 \\
\hline 17 & 0.0128 & 17 & 18 & 0.006769 & 0.00281 \\
\hline 18 & 0.0504 & 18 & 19 & 0.012793 & 0.005306 \\
\hline 19 & 0.0504 & 19 & 20 & 0.011289 & 0.004686 \\
\hline 20 & 0.02 & 20 & 21 & 0.029355 & 0.012182 \\
\hline 21 & 0.0504 & 7 & 22 & 0.012793 & 0.005306 \\
\hline 22 & 0.0128 & 22 & 23 & 0.009025 & 0.003744 \\
\hline 23 & 0.08 & 23 & 24 & 0.007521 & 0.003124 \\
\hline 24 & 0.0128 & 24 & 25 & 0.00376 & 0.001562 \\
\hline 25 & 0.0504 & 25 & 26 & 0.003008 & 0.001248 \\
\hline 26 & 0.0504 & 8 & 27 & 0.004512 & 0.001868 \\
\hline 27 & 0.0504 & 27 & 28 & 0.002256 & 0.000934 \\
\hline 28 & 0 & & & & \\
\hline
\end{tabular}

